\title{
Nuclear power - is the health risk too great?
}

\author{
B E Wynne School of Independent Studies, University of Lancaster
}

\section{Editor's note}

Apparently objective and value-free 'scientific' assessments of health risks are often highly value-laden and incorporate contentious social assumptions. Mr Wynne exposes some of the complexities underlying attempts to compare the health risks of nuclear and other sources of energy.

'The risk to human health or life is obviously only one of many factors which must affect our decisions on the suitability of different methods of electricity production. Any such choice will always be greatly influenced by many other considerations, such as economic constraints or the availability of resources and skills. It will also be governed by public acceptability of the source, and of the kinds of occupational or public hazard that may be involved. An important component in the decision however, must or certainly should depend upon an objective assessment of the total risk to be expected from each available type of fuel' ( $\mathrm{I}$ ).

In such balanced terms does Sir Edward Pochin, elder statesman of the British (and international) radiological protection system, approach the question of the appropriate role of medical knowledge in the ethics and politics of energy policy. Yet this kind of circumspection is shared by all too few participants in the energy debate. On the one hand, nuclear proponents uncritically purvey any favourable numerical comparison as overwhelming confirmation of the objective superiority of nuclear power; on the other, opponents often seem to fantasise about the scale of radiation risks, or refuse to lend them any significance whatever alongside other points more pleasing to their cause.

Very few people are interested in the pure question of what the health risks of nuclear power are: my own view is that even if the highest current estimates were established they alone would not cause people to fear nuclear power, so long as everything else was felt to be satisfactory. But of course the latter is far from the case: and if there are inadequate means of expressing these less technical concerns, it is inevitable - and in a certain sense, rational - that they be tacitly displaced onto apparently more concrete and tangible arguments such as health risks. After all, this apparently irrational displacement has also characterised pro-nuclear argument from the earliest days, when vague but powerful symbolic concerns equating nuclear power with civilisation itself were converted into tangible but empirically dubious public assertions about economic advantage, proven energy need, etc.

I shall therefore not attempt to give a direct answer to the title question, but instead do some necessary preliminary spadework to a direct answer - to discuss the wider context in which the debate about health risks takes place. I shall attempt to do this bearing in mind that this is a journal of medical ethics, and asking the reader in turn to bear in mind that I have no qualifications in medicine, and no special qualifications in ethics.

My approach is coloured by an established professional interest in the role of scientific expertise with other factors where that expertise is enlisted in political or moral issues. The ethical questions which surface in this paper will therefore tend to be general ones:

I) how far should professional experts prosecute the 'facts' of their area of expertise in relation to other scientific, moral, or social inputs to policy decisions; 2) in an area where scientific judgments of risks have to be interpreted into social judgments of acceptable levels of risk to be imposed in radiation standards etc, how much control should scientists exercise over the latter process;

3) what are the responsibilities of the experts for public education about such issues so as to aid constructive participation (including an understanding of when to leave a question to the experts);

4) what are the ethical and intellectual challenges posed by the need to understand and communicate types and degrees of uncertainty to other experts, policy makers and the public; and

5) in a strongly polarised and emotive social debate, what are the problems confronting the scientist who may wish to play a constructive role in both scientific and social contexts, between which the criteria of knowledge and argument differ considerably?

I cannot consider each of these questions systematically, let alone provide definitive answers, but I hope that some useful reflection can at least be stimulated.

The questions raised above are not unique to radiobiology nor even to medicine. There is a growing list of 
social issues where the environmental effects of different technological developments have called for systematic inputs of mature scientific or medical knowledge, yet have exposed the immaturity of the relevant fields of research (2). Even when research is relatively well developed however, as in the case of radiation risks, there always remain sufficient conflicts, gaps and uncertainties to sustain vigorous debate, not to say extravagant polemics (3). Whether the ranges of uncertainty are significant for social policy about energy choices, or whether the intensity of debate reflects symbolic battles or academic self-indulgence, is an interesting question. The most difficult problem of all is probably not a scientific one, but that of developing a sense of perspective as to what the radiation-risk debate means. This is a task in which the public needs the help of the expert, but in which equally, the expert needs the help of a clear-headed public, or its representatives. Not only is it a problem for the public that the experts appear to speak in a babble of tongues, but it is also the case that the experts can no longer assume a clear social definition of their role.

\section{The Nuclear Debate}

Ever since the earliest days of nuclear power, the question of radiation risks has been a key element of concern. It was brought to the fore in the r 950 by the awful realisation of the delayed effects of the radiation exposures suffered by the Japanese A-bomb survivors, and by the scientific arguments which raged over the effects of the fall-out from atmospheric nuclearweapons testing. The latter have recently re-surfaced in political arguments about the credibility of survival programmes following a nuclear war (4), but also in the scientific debates about the medical risks from radiation exposure of whatever kind - radiography, civil nuclear power, or even high natural-background radiation.

It is only since the early I 970 s that significant largescale opposition to civil nuclear power has developed. The earlier Campaign for Nuclear Disarmament, for example, was expressly not against civil nuclear power, believing that if suitably controlled, the latter's growth did not imply nuclear weapons proliferation. Since the rush to develop or import nuclear technology following the 1973 oil crisis, and with a small but growing list of cases where civil and military nuclear developments or intentions cannot be disentangled, one of the greatest concerns over international nuclear power development is now the 'social risks' of the proliferation of nuclear weapons into highly unstable political areas such as South Africa or the Middle East.

Added to these are new concerns: about the risks of terrorist attacks or even blackmail threats against civil nuclear installations, and the possible undermining of civil liberties which might follow from attempts to curtail such risks; and about the social and economic vulnerability and authoritarianism that might be entailed by the degree of centralisation required to render nuclear power efficient in its own terms. Even the economics of nuclear power have been called into question. Its glowing promise of the I950s was for 'electricity too cheap to meter', on tap like water (5). Indeed the economic argument indicates something of the convoluted nature of the issues. It is estimated that the largest proportion of the huge escalation of nuclear-power costs in the USA in the early I970s was due to extra safety measures and environmental controls arising out of concern over radiation risks (6). Also, the huge capital investments involved in nuclear power mean that even to have a chance of being economic, large commitments have to be made; yet inevitably this means large distortions and inflexibility in the political management of public investments, and also colossal pressures to export sensitive nuclear plant even to suspect customer countries such as Iraq, or environmentally dangerous places (because of earthquakes) such as the Philippines (7). Thus the questions of the health risk, the economics, and the politics of nuclear power can be seen to be inextricably connected.

Even the accident safety question, which had subsided for a time after the influential US Rasmussen Report in 1975, has been re-opened following the widespread criticism of that report's pro-nuclear bias which eventually led to withdrawal of endorsement in I 979 by the US authorities. Three Mile Island and recurrent instances of lax management at the Windscale re-processing plant in Cumbria have also focused attention on the question of accident safety.

The nuclear debate has thus broadened and differentiated dramatically in the last decade, and many of the issues now on the agenda defy the kind of secure quantitative conclusions which scientific analysis may provide. Assessments of the risks from weapons proliferation or civil liberties erosion due to civil nuclear power must inevitably remain speculative, and qualitatively distinct from assessments of risks from radiation exposures due to routine waste releases. Although they are frustratingly unquantifiable however, these broader considerations may ultimately be more important. Even the accident safety question - ultimately one of health risk - stumbles into such wider problems because to estimate the risks, assumptions have to be made about the reliability of human designers and operators, and about the behaviour of workers and would-be assailants in future social conditions which are unpredictable. The waste disposal issue is similar in principle.

In such circumstances, the role of any scientific conclusions about the radiation risks (even as compared to those of other energy systems) is highly uncertain, and open to differing assessments. How does one relate extremely detailed, sophisticated evaluations of radiation risk to social concerns about nuclear proliferation or creeping political authoritarianism which are inevitably speculative, and difficult to attribute in any causal sense, yet which if valid, would be utterly drastic compared to the conceivable health risks? One might indeed be forgiven for re-phrasing 
the title question - 'Is the health risk relevant?'. Clearly it is, but to what relative extent - and how to relate the different qualities of risk involved - is a central problem. It is also one which the scientist who becomes involved cannot ignore, because there is a natural professional tendency to dismiss the less quantifiable possibilities as vacuous, and to imply, deliberately or not, that the quantifiable arguments are the only important ones (8). In the perspective of the public or policy makers, who have to take account of the broader questions, such an implication, even inadvertently made, can only discredit the scientific judgments of those who make them. As is so often the case in social affairs, there is no agreed idea of what the issue really is, and the scientist's understandable enthusiasm for offering facts has to be tempered by the realisation that this is tantamount to a claim to define the social issue in such restricted terms. One is then inevitably straying beyond the bounds of professional neutrality, however neutral one may be in motivation. The difficulty for scientists involved in such problems is formidable.

Consider the safety and waste disposal issues for example. A risk analyst may take a scientific approach to estimations of the probability of different possible accident mechanisms such as the failure of pumps in the coolant circuit or the fracture of pipes due to weldfailures etc. Fault-tree analysis can provide a reasonably rigorous, very sophisticated means of aggregating such risks in different types of nuclear reactor, and the overall accident risk (deaths per reactor year) estimated as the integrated product of the probability (incidents per reactor year) and consequence (deaths per incident) of each possible accident mechanism. In such calculations however, the analyst may assume for example, that operators are totally alert all the time, and perfectly trained; that workers who control vital equipment will not strike; that terrorists will act 'rationally' and go elsewhere; that evacuation will be carried out without any hitches, and so on. The problem is that what may be universally accepted, taken-for-granted social assumptions of this kind at one time, may be far from so a few years later. This leaves the scientific expert exposed to political criticism that in neglecting alternative social possibilities, he has illegitimately biased his analysis, despite the likelihood that he has been as objective as he possibly could have been.

Even in the relatively more distinctly scientific field of radiobiology, scientific evaluations are open to social assumptions; for example if one states the risk from one manrem of whole body dose as $\mathrm{I}$ in $10^{4}$, what does this say for the child, or the person who is abnormally sensitive for other possible reasons such as smoking, allergies or infections, etc? Behavioural assumptions are also routinely made about recording of causes of death, and the currently debated dosimetry of the Japanese survivors relies upon a host of social behavioural assumptions. One can reply to the former point that, being taken from observations on 'average' populations, these risk figures cover such abnor- mal cases in their overall magnitudes. As long as they are stated as mean figures there should be no problem. Whether or not they are indeed taken from average populations however - and there is scientific dispute about this - it is clear that even in this field scientific judgments or statements may contain elements of social assumption. To advance mean risk figure for example in the context of a debate about radiation standards may be to advocate the social view that standards should be set against 'average' risk rather than 'most vulnerable' risk. To the extent that this is disputed as a value judgment, the scientific statement itself may be viewed as biased. The dilemma for the scientist here is that, in order to demarcate a purely scientific position free from any social contamination the objective professional ideal - one would have to explicate every assumption underlying every scientific statement. Not only might this prove impossible (we do not recognise many assumptions as such because they are so familiar that they are embedded in our thinking), but it would be so pedantic and complex as to render the ensuing statements useless in social debate or decision-making (9).

\section{Comparative risks}

So far I have indicated one broad set of considerations that affect the role of the medical expert in the energy debate, and which have to be confronted in order to address the question whether the health hazard of nuclear power is too great. There are qualitatively different risks, and sets of risks associated with each energy technology also come in different constellations. It is difficult to discern where risks change from 'health' to something else, such as 'social' (eg economic failure, or authoritarian government), and it is difficult even to compare cancer deaths from controlled long-term routine discharges of radioactivity, with cancer deaths from a single large accidental release which might traumatise a whole nation.

In this section I shall discuss some of the problems which arise in attempting to make quantitative comparisons of the health risks of different energy technologies. If this appears to be critical even of the attempt at comparison, I should emphasise that my aim is only to outline some of the considerations that if borne in mind would help to place such comparative approaches in balanced perspective, and thereby ensure that they are not rejected due to uncritical usage. Comparative risk approaches must of necessity remain numerically crude, because the 'qualitative' considerations outlined below may render any attempt at greater precision quite meaningless, indeed downright misleading. Here lies a dilemma for the scientist, whose very professional identity is founded on the constant search for greater precision.

I undoubtedly do not fall on the side of the angels in Pochin's classification - 'there are those who talk so much about the theory of risk that no numbers ever emerge; on the other hand, there are those who talk so much about acceptability that no numbers are judged 
relevant; I advocate the need also for the humbler middle course, of simply estimating the size of risks' (Io). Whether that honourable and valuable attempt to develop numerical sophistication can maintain innocence-with-relevance is a question of some importance.

It is common nowadays to see tabulated figures for the risk from different energy technologies estimated in terms of deaths from routine operations per unit of energy produced (II). On this basis it is usually emphasised that coal is far more damaging than nuclear power, the conclusion being that nuclear power should at least partly replace coal, or at least that it is therefore acceptable. Let us look at some of the qualifications and mis-perceptions in this line of argument:

I) The emissions from a coal-fired power station are often compared to those from a nuclear power station. Coal burning produces oxides of sulphur and nitrogen, and even radioactivity from impurities in the coal. The first misleading aspect of this comparison is that nuclear power stations are only a very small part of the full operations producing nuclear electricity. Whereas coal burning has to be integrated with coal mining to assess the full risk, nuclear power stations have to be integrated with uranium mining, and mill tailings, fuel enrichment and fabrication, spent fuel storage and reprocessing, and waste disposal. Some would also argue that one should include a share of overall accident risk for each reactor, and logically, if one believes that civil nuclear power adds to the likelihood of nuclear war, a share of the health costs of this too.

Even if one discounts the latter two components of the risks of a nuclear power station, the misleading nature of the comparison of power station with power station is emphasised in the fact that nuclear power stations are by far the cleanest part of the full nuclear fuel cycle - for example, about 98 per cent of all the radioactivity emitted from British nuclear plants is from the one Windscale reprocessing plant (there are eleven nuclear power stations, one fuel fabrication, and one enrichment plant contributing the other 2 per cent) (12). There is no equivalent for a coal station.

2) Some pro-nuclear scientists such as Fremlin (13) have even attempted to suggest that the radioactive emissions and population doses from coal burning are significant, yet on a fuel-cycle-to-fuel-cycle comparison, they are about 400 times less than those from nuclear power.

3) It is always necessary to know whether the emissions from the technologies being compared can be reduced easily or not. It may be better to clean up a dirty technology if this is easy, than to choose an alternative. Bare comparisons of risk from emissions conceal this point. Thus for example, the standards for coal purity and cleaning of emissions have been tightened considerably in the last few years in the USA, and it has been estimated that installed lime scrubbers in coal power stations could cut the harmful sulphur emissions to a tenth. Cross-examination of British Nuclear
Fuels Ltd (BNFL) at the Windscale public inquiry did not produce any evidence that the reprocessing plant could have its emissions cut, although BNFL promised that they could, even for the much higher throughput of radioactivity being planned. The only historical evidence is that in 1970 they asked for (and received) freedom to discharge more $\alpha$-emitters, and the designed discharge targets for the present magnox plant when it was commissioned in 1964, were exceeded by about ten times after only six years. Whether the nuclear fuel cycle is open to easy improvement therefore remains open to doubt, whereas for coal there are known technologies available which could cut the risks considerably (I4).

4) The calculation of health risk has become so sophisticated on the surface that the costs of estimated deaths are computed into cost-benefit equations. An analysis of this enterprise in ethical terms is worth a book in its own right, but here I shall point out only that whereas some emphasise that cancer deaths may only shorten life by a few years, thereby 'reducing the cost' of such deaths, the same can be argued for coal deaths, since most of the deaths due to coal are from sulphur dioxide emissions, which cause death mainly to elderly people, especially those already suffering from bronchial disorders. My own view would be that such fine calculations, quite apart from the cold-blooded view of human suffering which they take, begin to become pretentious and irrelevant when taken to such levels of sophistication. In answer to very specific questions such exercises may be valid, but not in any pretence at a direct answer to the title question, because the assumptions one makes so strongly colour the 'factual' answers one finds, and because the uncertainties of attribution and omissions (eg morbidity) may be so large as to render absurd the apparently scientific precision of the figures.

5) One important study by Inhaber (15) which purported to prove that the health risks of nuclear power were smaller not only than coal and oil but than renewable energy sources such as wind and solar power, exhibited these and other misleading tendencies. Inhaber not only took out-of-date, and thus much dirtier coal standards as the basis of comparison with nuclear power, but he assumed that nuclear waste disposal - a future technology as yet undeveloped would produce zero health risk. Not only this, but when he added up the risks from solar or wind electricity he assumed that they would be used for base-load electricity (rather than their projected use as intermittent but 'free' fuel-savers), and assumed that they would have dirty coal burned as a back-up when it was cloudy or windless. Thus 85 per cent of the health risk attributed to solar energy and 75 per cent of that attributed to wind energy was actually from dirty coal, though this was not evident in the tabulated comparative figures. Even if one accepted Inhaber's dubious assumption that the intermittent renewable sources would be installed as base-load systems, critics pointed out that on this way of calculating, if he had taken gas 
as the back-up, the estimated risks would have been drastically reduced.

Various other questionable assumptions and interpretations of source-data, all systematically in favour of nuclear power, led Inhaber to his conclusions, which were presented in a scientific, numerical form that belied the questionable choices he had made on the way. The report and its conclusions were widely disseminated by the worldwide nuclear industry and eminent friends (such as Lord Rothschild in the BBC TV Dimbleby Lecture, 'Risk'), without any hint of the criticism which it was receiving from qualified experts. There was not the slightest suggestion of waiting in the normal professional way, for critical review and rejection, acceptance or modification by peers. In response to gathering expert protest, the report was later quietly withdrawn by its sponsors, the Atomic Energy Control Board of Canada. By then however, it had already served the 'scientific' purpose of public persuasion for which it was enthusiastically employed.

\section{From physical risk to social perception}

One further example taken from the Inhaber report illustrates the great difficulty in demarcating factual statements and questions from social ones, and thus emphasises the dilemma for the scientist wishing to remain objective and factual, yet socially relevant. In calculating the occupational health risks of different energy systems, Inhaber employed the units of health costs (man-days of work lost) per unit of energy produced. This is thoroughly scientific. Nevertheless if one technology employs say, four times as many as another per unit of energy, its risk per 1000 workers employed is relatively four times less than in the previous units. The units employed lend different perspectives to the risks involved. To be strictly thorough, one ought to ask what the net risks are to a given cohort, if it all works in energy industry $A$, or if one quarter works in energy industry B and three quarters work elsewhere, or are unemployed, etc. Here one can see that the calculation absorbs social assumptions again, and as soon as one follows it even a little it becomes manifestly absurd. Even restricting ourselves to health risks, how do we know where the balance of working population might go? Do we include depression or suicide from unemployment, or transport deaths from 'new' patterns of community, or the health costs of relative poverty such as less food or heating, etc, etc, ad absurdum? If one includes other costs such as economic and social ones, the problem is even worse.

The general point is that the factual aspect of risk is only one component absorbed in an infinitely more complicated web of social experiences, facts and objectives. Nor is it necessarily enough to say: 'Let us present the facts alone, and leave acceptability questions out of it'. The facts as presented may already harbour implicit social perceptions which may be open to choice and dispute. Coal miners accept very high levels of risk because, brought up in pretty monolithic traditional communities, that is where they obtain their life's meaning as well as their only livelihood. We all 'accept' daily carnage on the roads because driving is a part of social life to which we have become deeply accustomed, and because we have many ways of reasoning that the average risks (if we know them) do not apply to us - we wear seat-belts/do not drink/are over $25 /$ etc. This is emphatically not to defend the risks of such practices and glorify ignorance or blind tradition. But it does go some way towards explaining why a coal-miner might accept high risks rather than become unemployed, or have to move home. Decision-making at the level implied by the title question is, effectively, choosing between different forms of social existence. With such levels of technology as prevail nowadays, we do not use technology, we live it; it is a way of life. Calculating the 'facts' of competing technology such as risks is only one part of social reality, albeit a valid and useful part.

Although it is usual to attribute this kind of broadening of the risk issue to the 'irrational' public, or to anti-nuclear critics jumping from a sinking argument to something else, it is worth just recalling that no less a nuclear enthusiast than the Prime Minister, Mrs Thatcher, expressly believes in nuclear expansion because it will she hopes, diminish the political/social risk of coal arising from the dominant industrial might of the miners, who are not loyal Conservative voters. Unless health risk comparisons show some colossal differences between alternatives, other factors dominate real decisions.

It is worth examining the question of public 'irrationality' in risk perception a little further. A widely used method of putting nuclear risks in perspective is to compare them with commonly accepted risks in various walks of life, such as car driving, air travel, rock climbing or merely living at the age of 60 . This is fair enough for perspective, but as many people have pointed out, there are rational grounds for accepting lower risks for example from activities over which one has no control, (eg energy production from power stations) than from those where one can choose for oneself whether and how to impose or withdraw from the risk (eg driving). There is more to it even than this however, because the risks from, say, a given nuclear power station cannot in reality (as opposed to logical abstraction) be divorced from those which it may entail in the form of future, more widespread nuclear developments. The same is true for any other single development, depending (a) on the extent to which its technology is interconnected eg as the nuclear fuel cycle and its successive systems are, and (b) on the degree of power which its promoters enjoy.

The last point is important because if people judge that they have little control over present and future developments, they will quite rationally evaluate any single plant as if it embodied those future developments and their attendant social and health risks too. On the face of it therefore, they will hold an 'irrationally' high estimation of the risks from a single 
development, as measured by factual analysis eg of probable deaths. Yet understood in context, this overloading may be quite rational. The real problem arises if people do not understand the basis of their own reasoning, and falsely express it as a factual claim about the specific risks of that single development. The problem for the scientist here is that although it is valuable to clarify the basis of arguments by introducing whatever facts are available (even if they are only in terms of ranges and probabilities), putting the bare facts without explicit recognition of the founding social assumption - that the single development does not in reality encourage expansion into others - is laying oneself open to legitimate criticism of unscientific bias, because the assumption is disputable, and a matter of sociological interpretation.

The same kind of analysis can be conducted of the symbolic association of civil nuclear power with nuclear weapons. Not only is there a historically real association between the two, but there remains a case for arguing that civil nuclear energy can never be, or is not being, politically controlled to limit the risks of nuclear weapons proliferation. One cannot do justice to the arguments for and against that view here, but my point is only that the case is a respectable one. Again, if that view leads, by a psychological displacement process, to implicit inflation of specific claims about health risks from nuclear developments, then scientific facts about risk levels may have an important role to play in clarifying the grounds of argument. Usually however, they are advanced in ways which suppress development of deeper issues.

A specific example can be given of the importance of social assumptions about the future controllability, technological competence and so on, of nuclear power promoters. It has already been pointed out that in stating risk figures even for present energy systems, one has to make assumptions about how modern, efficient, and immediately improvable they are. In attempting to address the title question, one has to make assumptions about the scale of nuclear power deployment one is talking about. At present, nuclear energy accounts for only about three per cent of UK primary fuel-use (about Io per cent of electricity supply). The average dose to UK individuals from this scale of nuclear power production is far less than that due to natural background radiation (about 80-150 millirems), even though small critical groups of people exposed to particular pathways such as fish-eating receive more than natural background (radiation workers receive up to 5 rems per year).

Thus, neglecting for the moment the question of occupational exposure, it appears that the average risks from nuclear power production are very low, and acceptable. However, quite apart from the assumptions this statement makes about unknowns such as waste disposal, it also begs the social question: 'Is the present scale of nuclear activity "stable", or does it entail expansion, and if so, what expanded scale should we try to evaluate in terms of its attendant health risks?' Taking the present scale as one's scientific starting point is inevitably to take sides in a social conflict as to how controllable is nuclear development, and assuming development - how competent is the industry to develop the technology to the much more efficient levels of emissions control required by greatly expanded throughputs of radioactivity. It has been estimated for example, that even average doses to the whole UK population would be about half of natural background on the UK Atomic Energy Authority's projected expansion of nuclear power by the year 2000 (I6). If this sounds low enough, we should remember that this would imply that critical groups would be exposed to much higher doses, and also that this would be in addition to natural background, and to other important or inevitable exposures such as those from other national nuclear programmes. Furthermore, if radiation risk estimates were five times too low (well within the range of dispute), average population doses would exceed natural background doses.

It may be of course that such health risks would still be regarded as trivial compared to others, either from competing energy systems or from familiar and accepted life activities. The point is that to make a meaningful statement the expert has to make social assumptions, and it is frequently these which are the focus of legitimate dispute. If the expert is not careful to identify and explicate these assumptions, then he is open to valid charges of bias; if he does, then even in the unlikely event that none have been overlooked, the chances are that his statement will be so hedged with qualifications and caveats that little notice is taken of it in social decision-making.

\section{Conclusions}

I have refrained almost entirely from discussing the conflicts and uncertainties which prevail in the scientific analysis of radiation risks. The scientific debate is strongly coloured by the social context in which it takes place, namely the polarised and emotive debate about nuclear power. Thus for example, although it is far from clearcut, scientific opinion about the threshold or non-threshold nature of the dose-response relationship tends to be structured around those who believe that radiation standards are adequate and that the public has an irrational fear of radiation, and those who believe that the radiation standards should be tighter (17). Despite the opportunities for chronic scientific differences of opinion however and despite the intense heat of the arguments, it remains probable that at the end of the day, the possible variations in health risk (the highest sustained and serious criticisms of prevailing risk estimates imply that they may be about 20 times too low) would not be very important in a comparative perspective. Although there are specific areas where higher accepted risk estimates would impose large economic penalties (and may be the straw that would break the camel's back) such as occupational 
protection (18), the intensity with which prevailing scientific views are defended (I9) seems to reflect a perhaps well-grounded fear of public reaction to news that previous ideas were wrong. It also seems to reflect a symbolic battle, of the kind not usually associated with scientists, to defend the reputation and authority of the institutions and scientists who have endorsed prevailing scientific judgments. The political context of the scientific debate leaves little freedom for scientists and 'regulatory' bodies such as the International Commission on Radiological Protection to change their views as evidence and interpretation develop and change. Instead the chances that such flexibility would be treated as evidence of previous neglect or incompetence are so strong as to effectively entrap scientists in this area into zealous defence of prevailing views. It requires only a very few episodes in which claims of low risk-estimates are shown to have been at best premature or flimsily grounded (whether or not in the end they are correct), to set a climate of mistrust which would poison dispassionate analysis, recognition of ignorance, and collaborative effort to explore uncomfortable possibilities.

Full scientific determination of the dose-response relationship at dose levels typical of exposure from nuclear power operations (less than I rem) will probably never be possible given: the small and atypical populations exposed to doses that small; the difficulties of estimating doses with any accuracy; the impossibility of assigning even definitive health-effects such as cancer or clinical genetic diseases, let alone sub-clinical effects, to possible exposures many years before when many other agents give rise to the same effects; and the difficulties in extrapolating from studies of higher doses and dose-rates down to lower doses and doserates. In the face of these and many more detailed uncertainties and options for judgment and interpretation, there is ample scope for endless difference of opinion about radiation health risks (20).

An intractable point of conflict in the translation of scientific knowledge into public policy is the difficulty of knowing which areas of scientific expertise are relevant, and whether the institutions involved, such as advisory committees, give a proper representation of scientific opinion in the area. This has been a chronic problem underlying the environmental lead controversy for example. In radiation risks also, various scientific specialties, each with very different methodological approaches, explanatory 'cultures' and specific objectives, have to co-exist and compete for sovereignty over the issue. Is a clinical radiologist or a biophysicist for example, fit to evaluate the theories of Stewart and others that low-level radiation damages the immune system, thereby causing various ordinary infectious diseases which can be lethal but which are never attributed to radiation (2I)?

A major problem is that quite properly scientific norms usually dictate a cautious and conservative attitude to new data and hypotheses. Yet the trends of new evidence have nearly always been towards higher risk estimates, and it is socially valid to base protection standards on 'reasonable possibilities' about evidence still being evaluated, cross-checked, and so on. In other words, social reason may demand standards of 'knowledge' that are different, and less conservative than science normally demands. Scientists operating in this social context of debate vary in their judgment of what weight to attach to possible evidence of higher risks, and it is easy for the scientific debate to spill over into accusation and counter-accusation of unscientific bias, etc (22). Again, the boundary between science and politics is thin-to-vanishing.

Even supposing medical consensus, there are then similar areas of scientific dispute in assessing how different groups receive doses, of what quantity and quality, from given discharges of radioactive isotopes. A topical example is the case of plutonium absorption in the gut, where chemical ignorance of the valency of plutonium may allow a thousand-fold difference in absorption rates.

If one projects into the future, as is reasonable according to my earlier argument, further options for interpretation arise concerning the scale and rate of nuclear development, its control by responsive government, and its own competence to develop discharge control technologies - all of which affect the assessment of the health risk. Adopting a comparative perspective as one must, the question marks proliferate. Given the scale and complexity of modern technologies, they must be seen as forms of social existence not as tools - social software encompassing the hardware, and organised around it. Social judgment about control, and uncertainties about security, livelihood, etc, come to dominate more identifiably factual questions about health risk. Yet whilst we have well developed scientific institutions for exploring and expressing the latter, mature and balanced expressions of the former are not nourished by our education and political institutions, largely because of past domination of these by experts. The scientific expert has to operate in this confusing climate, yet is probably the least educated to understand it. This is a problem which contains very practical ethical dimensions within it.

\section{References and notes}

An earlier version of this paper was given to a symposium organised by the London Medical Group in March 1979. The author is grateful to the London Medical Group for their hospitality on that occasion, and to the other participants in that symposium for providing a valuable discussion of the issues of radiation risk.

(I) Pochin E. Biological risk involved in power production. Physics and technology 1980;11:93-110. See also Pochin E. Physics in medicine and biology 1980;25:1-12, and Pochin E. Fournal of the royal college of physicians 1978;12:2 10-2 18. 
(2) Primack J, van Hippel F, eds. Advice and dissent. New York: Basic Books, I974. See also Nelkin D, ed. Controversy. London: Sage, 1979, and Holton G, Blanpied W, eds. Science and its public. Dordrecht, Holland: Reidel, 1976.

(3) Many of these specific scientific issues were rehearsed at the Windscale Inquiry, especially in the evidence and cross-examination of Alice Stewart, Edward Radford, Roy Ellis and George Dolphin. These arguments are charted in their tortuous route through the daily transcript by Taylor P, Stott M. The Nuclear controversy. London: Town and Country Planning Association, 1980. A useful and authoritative summary of several criticisms of the 'official' scientific standpoint is contained in Morgan K Z. Bulletin of the atomic scientists 1978;34:30-4I. A debate between scientific critics and defenders of current radiation standards was held at Guy's Hospital in October 1979. Tenor of discussion was polemical in the extreme.

(4) Lyon J. et al. New England journal of medicine 1979;300:397-402. See also The Observer Review 1980 Aug 7, and a letter from Lindop P, Boag J W to The Times 1980 Aug 4.

(5) Burn D. The political economy of nuclear power. London: Institute for Economic Analysis, 1967.

(6) Bupp I and Derian J C. Trends in LWR capital costs in the USA: causes and consequences. Harvard: 1975.

(7) Lonnroth M, Walker W. The viability of the civil nuclear industry. London: Royal Institute for International Affairs, I 980.

(8) Ezrahi Y. The authority of science in politics. In: Thackray A, Mendelsohn E, eds. Science and values. New York: Humanities Press, I974.

(9) Polanyi M. Personal knowledge. London: Routledge and Kegan Paul, 1958. See also Polanyi M. The tacit dimension. London: Routledge and Kegan Paul, 1966.

(I0) See reference (I).

(I I) Royal Commission on Environmental Pollution. Nuclear power and the environment. Chairman Flowers B. London: HMSO, I976. See also: Health and Safety Commission. The hazards of conventional sources of energy. London: HMSO, 1978; Parker R. The Windscale inquiry. London: HMSO, I978; International Commission on Radiological Protection (ICRP). Problems involved in developing an index of harm. Publication 27, Oxford: Pergamon Press, 1977; Rothschild V. Risk. The Listener, 1978 Nov 20, and reference (I).

(12) See the annual reports of the Fisheries Radiobiological Laboratory, Lowestoft, Radioactivity in surface and coastal waters of the British Isles, for details of discharges and environmental pathways.

(13) Fremlin J H. Letter to The Times 1978 Apr I 8 and reply by Rotblat J. 1978 Apr 28.

(14) To their credit, the Health and Safety Executive (see reference ( $\mathrm{I}$ I) recognised some of these distortions in the figures for coal when used comparatively.
(15) Inhaber H. Risks of energy production. Ottawa: Atomic Energy Control Board of Canada, 1978. (Report AECB-II 19/REV-2.) See also Holdren J. Risks of energy production: a critique of the Inhaber report. Berkeley: Energy and Resources Group, University of California, 1980.

(16) Lindop P. Some aspects of radiation hazards, paper to the conference, Energy Futures and the Fast Reactor, South Bank Polytechnic, London, November 1978. It is also difficult to see how the regulatory authorities are putting pressure upon the industry to improve discharge performance since the most recent revision of standards in ICRP publication 26, I977, relaxes dose limits to several organs such as lung, red bone-marrow and breast.

(I7) The US National Academy of Sciences' Committee of the Biological Effects of Ionising Radiations' third report (chairman Edward Radford) seems to have run into this impasse. Its report was due in March 1979, but was referred to a special committee due to irreconcilable conflict on the main committee, where a significant minority group claimed that the majority report's emphasis of the linear dose-response relationship and its (relatively slight) revision upwards of previous risk estimates was unduly alarmist. See Radiation research 1980;84.

(18) Occupational standards are the main focus of conflict in the ICRP's latest review of standards. For example, even on current ICRP risk estimates, a worker exposed to the maximum allowable whole body-dose for 40 years would have an extra - above 'natural' - risk of contracting cancer of $I$ in 50. However, if upper estimates were valid, this would be about 2 in 5 , not very attractive betting odds. One also has to include the chances of receiving the limiting dose every year for 40 years, of course, or take the average annual radiation worker (Windscale) dose of about $\mathrm{I} \cdot 2 \mathrm{rem}$, giving odds of about $I$ in 10.

(I9) Mole R H. Radiation risks - a rejoinder. New Scientist I 979 May Io.

(20) See reference (I7) and Gloag D. British medical journal I980;28I: Nov 29: 1479-82; Dec 6: 1545-48.

(21) Stewart A. Childhood cancers and the immune system. Cancer, immunology and immunotherapy 1980;9: I I-I4.

(22) The controversy surrounding the National Radiological Protection Board Report R54, is a case in point. This claimed that epidemiological investigation of the Windscale workforce showed no excess of cancers over that expected on normal grounds, yet it excluded cancers in the very population of workers (those who had retired or left) which would be expected to show such effects. Even then statistical mistakes concealed a significan excess of myelomas. Although the overall impact of such changes or risk-estimate might be minimal, their symbolic impact would be very great. 